\title{
Enhancement of the antimalarial efficacy of amodiaquine by chlorpheniramine in vivo
}

\author{
Akintunde Sowunmi ${ }^{+}$, Grace O Gbotosho, Christian T Happi, Ahmed A Adedeji, \\ Olayinka M Bolaji, Fatai A Fehintola, Babasola A Fateye, Ayoade MJ Oduola
}

\author{
Department of Pharmacology and Therapeutics and Institute for Medical Research and Training, \\ University of Ibadan, Ibadan, Nigeria
}

Resistance in Plasmodium falciparum to amodiaquine ( $A Q)$ can be reversed in vitro with with antihistaminic and tricyclic antidepressant compounds, but its significance in vivo is unclear. The present report presents the enhancement of the antimalarial efficacy of $A Q$ by chlorpheniramine, an $H_{1}$ receptor antagonist that reverses chloroquine $(C Q)$ resistance in vitro and enhances its efficacy in vivo, in five children who failed $C Q$ and/or $A Q$ treatment, and who were subsequently retreated and cured with a combination of $A Q$ plus $C P$, despite the fact that parasites infecting the children harboured mutant pfcrtT76 and pfmdr1Y86 alleles associated with AQ resistance. This suggests a potential clinical appliation of the reversal phenomenon.

Key words: amodiaquine - chlorpheniramine - resistance reversal - malaria - children

Increasing resistance in Plasmodium falciparum to the presently available antimalarials has led to renewed search for alternative effective drugs or drug combinations and increased efforts to counter the growing problems of drug resistance. Amodiaquine (AQ), a Mannich base, more effective than chloroquine (CQ) on CQ-sensitive or CQ-resistant parasites, is frequently used in many parts of Africa as a component of combination antimalarials, or in some settings, as monotherapy. There is increasing evidence that $P$. falciparum resistant to AQ may be emerging in certain areas of Africa. In these areas, it would appear the genetic mutations in the parasite that confer reisitance to CQ may also confer resistance to AQ (Ochong et al. 2003, Happi et al. 2006).

Chlorpheniramine (CP), a histamine receptor type 1 antagonist, can reverse resistance in P. falciparum to CQ in vitro and in vivo (Sowunmi et al. 1997, $1998 \mathrm{a}, \mathrm{b}$ ). It can also reverse monodesethylamodiaquine (MDAQ) (the active metabolite of AQ) resistance in $P$. falciparum in vitro (Oduola, unpublished). Desipramine and calcium antagonists can potentiate the effect of CQ, AQ or MDAQ against $P$. falciparum in vitro (Kyle et al. 1990, Basco \& Le Bras 1991). Despite the potential clinical application of using CP or other potential resistancereversing compounds to enhance the efficacy of $\mathrm{AQ}$, there is no published study of the effects of $\mathrm{CP}$ or of other potential resistance-reversing compounds on the action of AQ following AQ treatment failure in African

Financial support: UNDP/World Bank/Who Special Proramme for Research and Training in Tropical Diseases

${ }^{+}$Corresponding author and WHO/TDR Career Development Grantee. E-mail: akinsowunmi@hotmail.com

Received 4 December 2006

Accepted 24 April 2007 children. In the present study, we report five children who failed CQ and/or AQ treatment, and who were subsequently retreated and cured with a combination of $\mathrm{AQ}$ plus $\mathrm{CP}$, despite the fact that parasites infecting the children harboured mutant pfcrtT76 and pfmdr1Y86 alleles associated with amodiquine resistance in Ibadan, Nigeria (Happi et al. 2006).

The study was conducted in Ibadan, a hyperendemic area of malaria in Southwest Nigeria, between September and December 2000. The five children were part of a cohort of 210 children aged $0.6-13$ years presenting with acute, symptomatic, uncomplicated, $P$. falciparum malaria who were, initially, randomized to, and were treated with CQ or AQ $30 \mathrm{mg} / \mathrm{kg}$ of body weight orally over three days (Sowunmi et al. 2001). All of the tablets were administered by a physician and each child was observed for at least $3 \mathrm{~h}$ after each such supervised treatment, in order to ensure that the drug was not vommitted. If it was, the child was excluded from the study. Following intial treatment with either of these drugs, all CQ treatment failures were retreated with AQ on day 7 or 14 , or whenever they became symptomatic. Similarly, all AQ treatment failures were retreated with AQ plus $\mathrm{CP}$ on day 7 or 14 , or whenever they became symptomatic. If an AQ treatment failure had low parasitaemia at the time of treatment failure, the child was kept under close observation until parasitaemia increased to appreciable level. CP was given orally at the dose used for the potentiation of the antimalarial efficacy of CQ in vivo (Sowunmi et al. 1998 b). Children less than 5 years received a loading dose of $6 \mathrm{mg} \mathrm{CP}$ maleate followed by 4 mg every $8 \mathrm{~h}$ for a total treatment period of 7 days. Children aged 5 years or above received a loading dose of 8 $\mathrm{mg}$ followed by $6 \mathrm{mg}$ every $8 \mathrm{~h}$ for the same period.

Follow-up with clinical and parasitological assessment was done daily for 8 days (days 0-7) and then on days 14,21 , and 28 at first treatment. In children treated with $\mathrm{AQ}$ plus $\mathrm{CP}$, follow-up was also done on days 35 and 42 except in one patient who was lost to follow-up 
after day 14. Response to drug treatment was evaluated as previously described (Sowunmi et al. 1998 b). Two drops of blood was blotted onto 3MM Whatman filter paper (Whatman International Ltd, Springfield Mill, Maidstone, Kent, England) at enrolment and during follow-up for extraction and analysis of parasites' DNA. Treatment failures were confirmed by $m s p$ - 2 genotyping of infections at enrolment and recurrence of parasitaemia as described previously (Happi et al. 2004, 2005, 2006). This step was necessary because of the practical difficulty to clinically discriminate between re-infections and recrudescent infections after day 14 (Happi et al. 2004) in this area of intense malaria transmission. The protocol for the study was approved by the Joint University of Ibadan/ University College Hospital Ethics Review Committee.

Matched sample pairs collected before and after treatment from the five patients who failed AQ treatment were successfully analyzed at the $m s p-2$ locus. Presence of different allelic families of $m s p$ - 2 was often found in parasite DNA derived from a single patient, indicating a polyclonal infection (varying from 2 to 6 ) (Table I). The estimated average number of genetically distinct parasite population as determined with $m s p$ - 2 in pre- and post-treatment isolates from these five patients was 4.6 (range 4 to 6) and 3.0 (range 2 to 4 ), respectively. There was a significant reduction $(\mathrm{P}=0.008)$ in the number of $m s p-2$ alleles in post-treatment isolates compared to pre-treatment isolates when infections recrudesced. All infections in paired PCR fragments but one (patient ID 050/2000) were identical at both FC27 and $I C l$ allelic families of $m s p-2$, indicating genuine recrudescent infections after treatment with $\mathrm{AQ}$. Recurrence of infection in this patient showed parasites similar to pre-treatment isolates and the presence of new parasite populations with different genotypes. However, we considered this infection as resulting from genuine treatment failure, because this patient failed treatment early (RII) when presumably AQ or MDAQ blood levels may still be high. Parasite isolates from all five patients at enrolment and when infections recrudesced, carried mutant $\mathrm{p} f m d r 1 Y 86$ and $\mathrm{p} f$ crtT76 alleles implicated in conferring resistance to CQ and AQ (Table I). Summaries of molecular characteristics of parasites and therapeutic responses during initial treatment with $\mathrm{AQ}$ and following retreatment with $\mathrm{AQ}$ plus $\mathrm{CP}$ are presented in Tables I and II, respectively. The parasite clearance times (PCT) were lower during retreatment with AQ plus CP

TABLE I

Molecular characteristics of Plasmodium falciparum isolates obtained from patients who failed amodiaquine treatment and were successfully retreated with a combination of amodiaquine plus chlorpheniramine

\begin{tabular}{|c|c|c|c|c|c|c|}
\hline \multirow[t]{2}{*}{ Patient ID } & \multicolumn{3}{|c|}{ Enrollment } & \multicolumn{3}{|c|}{ Recrudescence } \\
\hline & $\begin{array}{l}\text { Pfcrt alleles } \\
\text { at codon } 76\end{array}$ & $\begin{array}{l}\text { Pfmdrl alleles } \\
\text { at codon } 86\end{array}$ & $\begin{array}{c}\text { Multiplicity } \\
\text { of infections }\end{array}$ & $\begin{array}{l}\text { Pfcrt alleles } \\
\text { at codon } 76\end{array}$ & $\begin{array}{l}\text { Pfmdrl aleles } \\
\text { at codon } 86\end{array}$ & $\begin{array}{l}\text { Multiplicity of } \\
\text { infections }\end{array}$ \\
\hline $050 / 2000$ & $\mathrm{~T} 76^{a}$ & $\mathrm{~N} 86+\mathrm{Y} 86$ & 6 & $\mathrm{~K} 76+\mathrm{T} 76$ & $\mathrm{~N} 86+\mathrm{Y} 86$ & 3 \\
\hline $090 / 2000$ & $\mathrm{~T} 76$ & $Y 86^{c}$ & 4 & $\mathrm{~T} 76$ & Y86 & 2 \\
\hline $116 / 2000$ & $\mathrm{~K} 76^{b}+\mathrm{T} 76$ & N86 ${ }^{d}$ & 4 & $\mathrm{~T} 76$ & Y86 & 4 \\
\hline $134 / 2000$ & $\mathrm{~T} 76$ & N86+Y86 & 5 & $\mathrm{~T} 76$ & Y86 & 3 \\
\hline $141 / 2000$ & $\mathrm{~K} 76+\mathrm{T} 76$ & $\mathrm{~N} 86+\mathrm{Y} 86$ & 4 & $\mathrm{~T} 76$ & Y86 & 3 \\
\hline
\end{tabular}

Pfcrt: P. falciparum CQ resitance transporter; $p f m d r 1:$. falciparum multiple drug resistance 1 gene; $a$ : $p f c r t$ mutant allele (T76); $b$ : $p f c r t$ wild-type allele (K76); $c$ : pfmdrl mutant allele (Y86); $d$ : pfmdrlwild-type allele (N86). $e$ : clone multiplicity was determined using a polymorphic locus of $m s p$-2 (Happi et al. 2004, 2005, 2006).

TABLE II

Clinical and parasitological profiles of children with falciparum malaria resistant to amodiaquine and who were subsequently retreated with a combination of amodiaquine plus chlorpheniramine

\begin{tabular}{|c|c|c|c|c|c|c|c|c|c|c|}
\hline \multirow[b]{2}{*}{ Patient ID } & \multicolumn{5}{|c|}{ Amodiaquine } & \multicolumn{5}{|c|}{ Amodiaquine/Chlorpheniramine } \\
\hline & $\begin{array}{c}\text { Age } \\
\text { (years) } \\
\text { /Sex }\end{array}$ & 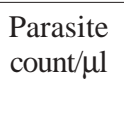 & $\begin{array}{l}\text { PCT } \\
\text { (d) }\end{array}$ & $\begin{array}{l}\text { FCT } \\
\text { (d) }\end{array}$ & Response $^{a}$ & $\begin{array}{l}\text { Parasite } \\
\text { count } / \mu l\end{array}$ & $\begin{array}{c}\text { Day } \\
\text { treatment } \\
\text { started }\end{array}$ & PCT (d) & FCT (d) & Response $^{b}$ \\
\hline $50 / 2000$ & $2.0 / \mathrm{F}$ & 48475 & - & 3 & RII & 8149 & 19 & 3 & 1 & S \\
\hline $90 / 2000 *$ & $6.0 / \mathrm{F}$ & 12328 & 2 & 3 & RI (14) & 8198 & 21 & 1 & 1 & $\mathrm{~S}$ \\
\hline $116 / 2000 *$ & $6.9 / \mathrm{F}$ & 10782 & 3 & 1 & RI (14) & 9731 & 21 & 1 & - & $\mathrm{S}$ \\
\hline $134 / 2000 *$ & 1.5./F & 17190 & 3 & - & RI (17) & 7760 & 17 & 2 & - & S \\
\hline $141 / 2000$ & $4.0 / \mathrm{F}$ & 54090 & 3 & 1 & RI (14) & 45654 & 19 & 2 & 2 & S \\
\hline
\end{tabular}

F: female; $a$ : day when recrudescence was detected is shown in parentheses; $b$ : follow up was 42 days except in patient ID 134/2000 where follow-up was for 14 days; *Failed CQ-treatment with RI (response); PCT: parasite clearance time; FCT: fever clearance time; S: sensitive; RI: parasitaemia clears completely but reappears within 14 days of follow up; RII decrease of parasitaemia below $25 \%$ of baseline, but no complete clearance from peripheral blood. 
than during initial treatment with $\mathrm{AQ}$, although group mean difference was not significant. Apart from drowsiness lasting $0.5-0.75 \mathrm{~h}$ following the first dose of $\mathrm{AQ}$ plus $\mathrm{CP}$ in all children, there were no other overt adverse drug effects. Haematological and biochemical parameters which included haematocrit level, full blood counts, and liver and kidney function tests, were within normal limits and were similar during the initial treatment with AQ and following retreatment with AQ plus CP.

We extended the use of CP for the enhancement of the antimalarial efficacy of CQ in CQ-resistant infections (Sowunmi et al. 1997, 1998 a,b) to AQ-treatment failures in five children with AQ-resistant parasites harbouring mutant pfcrtT76 and pfmdr1Y86 alleles and these patients had favourable treatment outcome. The mechanisms of the enhancement of AQ efficacy by $\mathrm{CP}$ or the clearance of drug resistant parasites by this combination remain unclear and the findings in the present study should be interpreted with caution because of the small number of children evaluated. However, should similar favourable outcome be observed in more extended, on-going studies of AQ versus AQ plus CP, deploying the latter in resource-poor communities still using AQ alone may be of some advantage pending the availability of artemisinin-based combinations in these resource-poor communities. Studies are also under way to assess the molecular basis of the reversal of AQ resistance by CP as well as the effects of CP on the disposition of AQ and its metabolite in children treated with AQ or AQ-based combination drugs.

\section{REFERENCES}

Basco LK, Le Bras J 1991. Potentiation of monodesethylamodiaquine and amopyroquine with desipramine against Plasmodium falciparum in vitro. Trans $R$ Soc TropMed Hyg 85: 447-448.

Happi CT, Gbotosho GO, Folarin OA, Akinboye DO, Yusuf BO, Ebong, OO, Sowunmi A, Kyle DE, Milhous W, Wirth DF, Oduola AMJ 2005. Polymorphisms in Plasmodium falciparum dhfr and dhps genes and age related in vivo sulfadoxine-pyrimethamine resistance in malaria-infected patients from Nigeria. Acta Trop 95: 183-193.

Happi CT, Gbotosho GO, Folarin OA, Bolaji OM, Sowunmi A, Kyle DE, Milhous WK, Wirth DF, Oduola AMJ 2006. Association between mutations in Plasmodium falciparum chloroquine resistance transporter and $P$. falciparum multidrug resistance 1 genes and in vivo amodiaquine resistance in $P$. falciparum malaria-infected children in Nigeria. Am J Trop Med Hyg 75: 155-161.

Happi CT, Gbotosho GO, Sowunmi A, Falade CO, Akinboye DO, Hudson T, Gerena L, Kyle DE, Milhous W, Wirth DF, Oduola AMJ 2004. Molecular analysis of Plasmodium falciparum recrudescent malaria infections in children treated with chloroquine in Nigeria. Am J Trop Med Hyg 70: 20-26.

Kyle DE, Oduola AMJ, Martin SK, Milhous WK 1990. Plasmodium falciparum: modulation by chloroquine, desethylchloroquine, quinine and quinidine in vitro. Trans $R$ Soc Trop Med Hyg 84: 474-478.

Ochong EO, Van Den Broek IVF, Keus K, Nzila A 2003. Association between chloroquine and amodiaquine resistance and allelic variation in Plasmodium falciparum. Am J Trop Med Hyg 69: 184-187.

Sowunmi A, Oduola AMJ, Ogundahunsi OAT, Falade CO, Gbotosho GO, Salako LA 1997. Enhanced efficacy of chloroquine-chlorpheniramine combination in acute uncomplicated falciparum malaria in children. Trans $R$ Soc Trop Med Hyg 91: 63-67.

Sowunmi A, Oduola AMJ, Ogundahunsi OAT, Salako LA 1998a. Enhancement of the antimalarial effect of chloroquine by chlorpheniramine in vivo. Trop Med Inter Hlth 3: 177-183.

Sowunmi A, Oduola AMJ, Ogundahunsi OAT. Salako LA 1998 b. Comparative efficacy of chloroquine plus chlorpheniramine and pyrimethamine/sulphadoxine in acute uncomplicated falciparum malaria in Nigerian children. Trans $R$ Soc Trop Med Hyg 92: 77-81.

Sowunmi A, Ayede AI, Falade AG, Ndikum VN, Sowunmi CO, Adedeji AA, Falade CO, Happi TC, Oduola AMJ 2001. Randomized comparison of chloroquine and amodiaquine in the treatment of acute, uncomplicated, Plasmodium falciparum malaria in children. Ann Trop Med Parasitol 95: 549-558. 
